\title{
MEMS reliability in a vibration environment
}

\author{
Danelle M. Tanner, Jeremy A. Walraven, Karen S. Helgesen, Lloyd W. Irwin, \\ Danny L. Gregory, John R. Stake, and Norman F. Smith \\ Sandia National Laboratories, P.O. Box 5800, MS 1081, Albuquerque, NM 87185-1081 \\ http://www.mdl.sandia.gov/Micromachine \\ email: tannerdm@sandia.gov
}

\begin{abstract}
MicroElectroMechanical Systems (MEMS) were subjected to a vibration environment that had a peak acceleration of $120 \mathrm{~g}$ and spanned frequencies from 20 to $2000 \mathrm{~Hz}$. The device chosen for this test was a surface-micromachined microengine because it possesses many elements (springs, gears, rubbing surfaces) that may be susceptible to vibration. The microengines were unpowered during the test. We observed 2 vibration-related failures and 3 electrical failures out of 22 microengines tested. Surprisingly, the electrical failures also arose in four microengines in our control group indicating that they were not vibration related. Failure analysis revealed that the electrical failures were due to shorting of stationary comb fingers to the ground plane.
\end{abstract}

\section{INTRODUCTION}

An element of the success of MicroElectroMechanical Systems (MEMS) as they reach commercialization depends on reliability studies and predictions. MEMS are typically classified as sensors or actuators. Brown et al. performed extensive experiments on MEMS acceleration sensors including shock, vibration, temperature cycling, and flight tests on artillery projectiles [1]. He saw promising results on automobile-grade accelerometers. However, sensors differ from microactuators in that they do not have rubbing surfaces. Surfaces in intimate contact during the environmental test may be at risk. This was demonstrated in reports on humidity effects and wear $[2,3]$.

Microactuators are used to drive many different types of devices from gear trains to pop-up mirrors [4]. During vibration experiments by Lee et al. $[5,6]$, reflected optical patterns from a clamped micromirror were monitored and were determined to be error free over a range of frequencies from $200 \mathrm{~Hz}$ to $10 \mathrm{kHz}$. They claim no effect from vibration of the clamped mirror on this scale.

But what happens when an actuator is not clamped and is free to move? Vibration causes motion in the actuator promoting the surfaces to rub and thus mimics normal operation. In addition, vibration perpendicular to the normal operation direction will impact guides or constraints. Both of these effects can generate wear debris leading to failure. One of the first experiments [7] to show wear as a dominant failure mechanism during operation ran polysilicon microturbines [8] and gears at rotational speeds up to $600,000 \mathrm{rpm}$. A focused air jet directed at the turbine induced the rotation. Previous experiments [9] on the lifetime of the Sandia-designed surfacemicromachined microengine [10] investigating frequency dependence revealed wear as the dominant failure mechanism.

We subjected our MEMS actuator to vibration. The microengine has springs that flex, guides that can be impacted, and surfaces that rub making it a good candidate for vibration studies. The resonant frequency of the microengine (about $1500 \mathrm{~Hz}$ ) is in the range of our system-requirement frequencies, which may be of concern. The objective was to determine any susceptibility of the microengine to vibration with the understanding that the results would apply to a broader range of MEMS actuators.

\section{EXPERIMENTAL APPROACH}

This study used the electrostatically driven microactuator (microengine) developed at Sandia National Laboratories [10]. The microengine consists of orthogonal linear comb drive actuators mechanically connected to a rotating gear as seen in Figure 1. By applying voltages, the linear displacement of the comb drives was transformed into circular motion. The $\mathrm{X}$ and $\mathrm{Y}$ linkage arms are connected to the gear via a pin joint. The gear rotates about a hub, which is anchored to the substrate.

\section{Sample Preparation}

Surface micromachined MEMS are mechanical structures fabricated from deposited thin films. The structures are encased in sacrificial layers (typically $\mathrm{SiO}_{2}$ ) until ready for use. The oxide film is etched away using hydrofluoric acid (HF) to yield a "released" sample. There are several strong adhesive forces that act on the structures during the drying stage of the release [11]. These include capillary, electrostatic, and van der Waals forces. Capillary forces dominate at these dimensions and processes have been developed to



Figure 1. Sandia microengine with expanded views of the comb drive (top left) and the rotating gear with a pin joint connecting to the linkage arms.(bottom left). 


\section{DISCLAIMER}

This report was prepared as an account of work sponsored by an agency of the United States Government. Neither the United States Government nor any agency thereof, nor any of their employees, make any warranty, express or implied, or assumes any legal liability or responsibility for the accuracy, completeness, or usefulness of any information, apparatus, product, or process disclosed, or represents that its use would not infringe privately owned rights. Reference herein to any specific commercial product, process, or service by trade name, trademark, manufacturer, or otherwise does not necessarily constitute or imply its endorsement, recommendation, or favoring by the United States Government or any agency thereof. The views and opinions of authors expressed herein do not necessarily state or reflect those of the United States Government or any agency thereof. 


\section{DISCLAIMER}

Portions of this document may be illegible in electronic image products. Images are produced from the best available original document. 
reduce or eliminate these forces for successful operation of the MEMS structure [12].

Coupling agent coatings such as alkysilanes have been used to increase the hydrophobicity of the polysilicon surface, thus eliminating capillary forces [13, 14]. Application of a coupling agent requires preparation of the polysilicon surface by an oxidation step $\left(\mathrm{H}_{2} \mathrm{O}_{2}\right)$, resulting in an oxide layer a few nanometers thick. The samples in this experiment were coated with such an alkysilane coupling agent.

\section{Microengine Vibration Experiment}

A die with four microengines was selected for this experiment. There were two microengines driving load gears and two microengines without load gears on the die. These microengine actuators included clamps to prevent out-of-the-plane motion. The dice were attached inside a 24-pin DIP ceramic package. A typical package without a cover is shown in Figure 2. The dice were packaged with taped glass covers during inspection and taped metal covers during experimentation to prevent particle contamination.

We used three modes of vibration, designated top/bottom, short side, and long side shown in Figure 2. With the top/bottom vibration, the moving shuttle could bounce between the ground plane and the vertical clamps. The motion could lead to possible problem areas of stiction to the substrate or impact wear of the clamps. The microengines are fairly well constrained by guides and spring stops against movement in the plane. However, resonance effects, with the associated large amplitude motions, could well be an issue for the short side and long side vibrations.

The orientation of the die relative to the vibration is shown in Figure 3. In both long side and short side orientation, actuators will be vibrated parallel or perpendicular to typical shuttle movement. When the motion is parallel, the shuttle and gear could move, lead- ing to wear of the rubbing surfaces. However, with perpendicular motion the shuttle hits the guides, which could promote wear from impacting surfaces.

Each functioning microengine was visually inspected and documented before the vibration by capturing nine video images of strategic areas. Four images were captured for each actuator, either $\mathrm{X}$ or $Y$, corresponding to different sections of the shuttle and comb mechanism. The final image was of the drive gear.

Because we were interested in establishing an upper bound to the susceptibility of MEMS devices to vibration, we chose a spectrum that was four times the typical system vibration requirement. Our design stress was a white noise spectrum with frequency components from $20 \mathrm{~Hz}$ to $2000 \mathrm{~Hz}$ and a power spectral density of $0.8 \mathrm{~g}^{2} / \mathrm{Hz}$. This range includes the resonant frequency of $1500 \mathrm{~Hz}$ for the microengine. The duration of the test was three minutes. Although the spectrum is very broad with random input frequencies and random microengine responses, most of the vibration-induced oscillation will occur at resonance [15]. Therefore we can estimate the total number of oscillations to be $1500 \mathrm{~Hz} \times 360$ seconds to be $5.4 \times 10^{5}$ cycles. This is equivalent to the typical number of stress cycles where we have observed failures due to wear in previous experiments [2,9]

The vibration spectra are shown in Figure 4, which includes a typical system requirement and the actual spectrum measured during the test. The rms values were calculated from the square root of the power spectral density times bandwidth. The peak acceleration is typically three times the rms value, yielding $120 \mathrm{~g}$ for this test.

The packages were clamped into a fixture as shown in Figure 5. The fixture was then attached to a mounting cube on the shaker table shown in Figure 6. Accelerometers were attached to the fixture to measure the vibration during test. The arrow in the figure indicates the vibration direction. The balance mass shown behind the mounting cube prevented out-of-plane stray oscillation. The three orientations were achieved by rotating the fixture on the mounting cube.

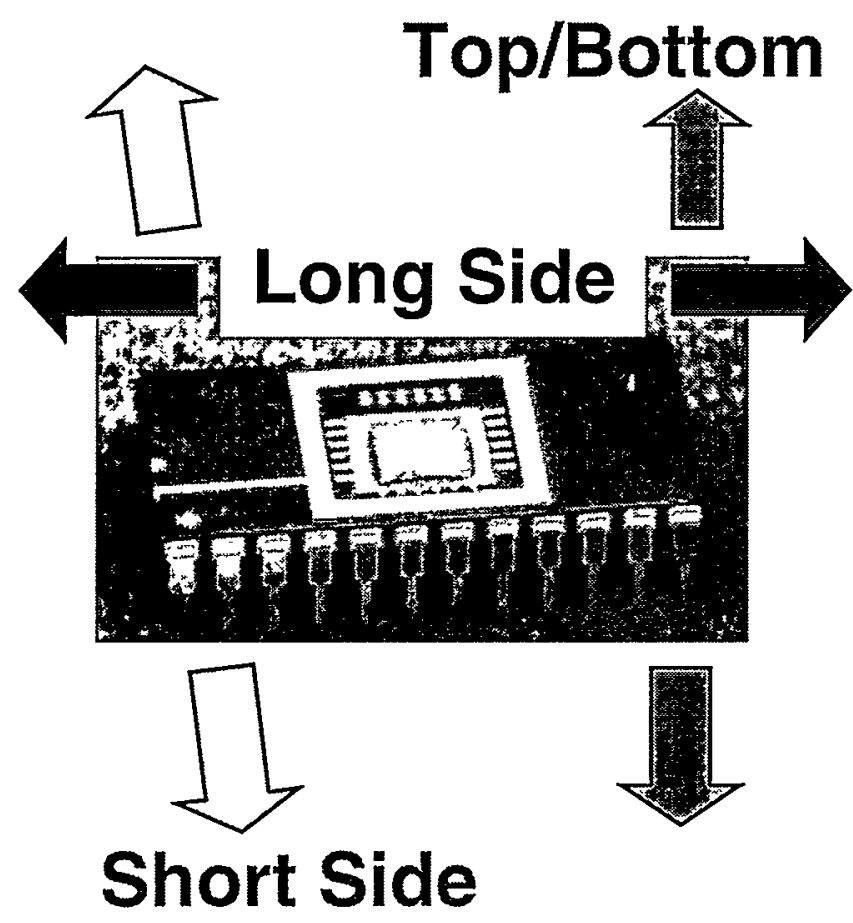

Figure 2. Photo of a typical packaged die that was vibrated in the three orientations indicated.

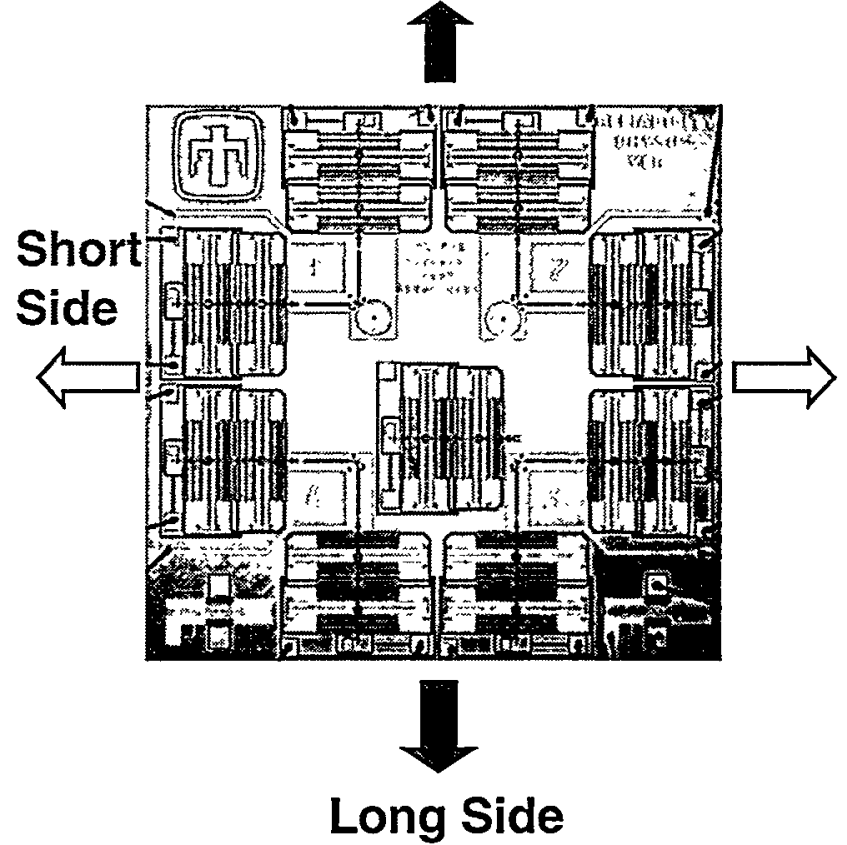

Figure 3. Orientation of the die relative to the vibration. 
- - requirement mast

acceleration peak is 3 times the rms value

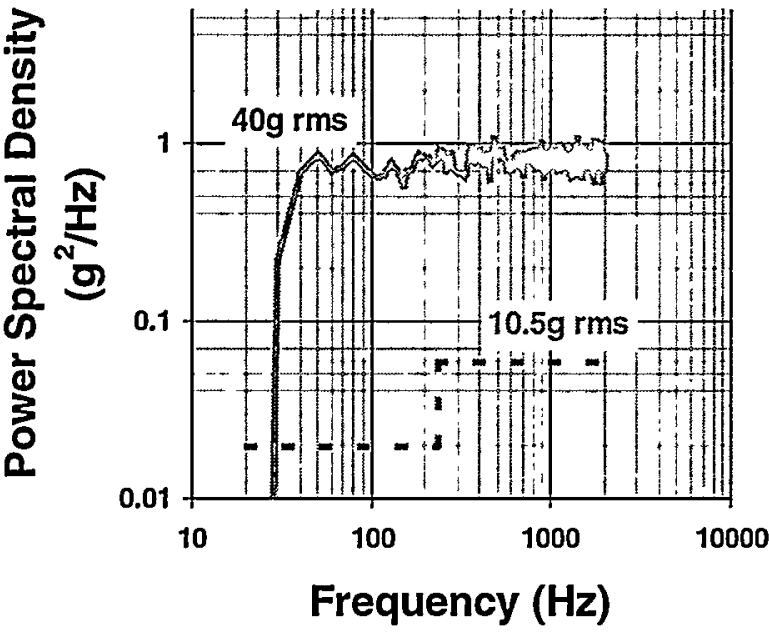

Figure 4. The graph of vibration spectra shows the requirement at $10.5 \mathrm{~g} \mathrm{rms}$ and the spectrum measured during the actual test.

The MEMS devices were unpowered during the test. Device functionality was checked both before and after the vibration test. The failure criterion was defined as the inability of the drive gear to make a complete revolution at the inspection frequency of $1 \mathrm{~Hz}$. The initial test had five functioning microengines in the top/bottom orientation, five microengines in the long side orientation, and 4 microengines in the short side orientation. An unusual device failure, which may have occurred independent of the vibration experiment (discussed in the Results section) prompted us to repeat the long-side orientation with an additional eight microengines.

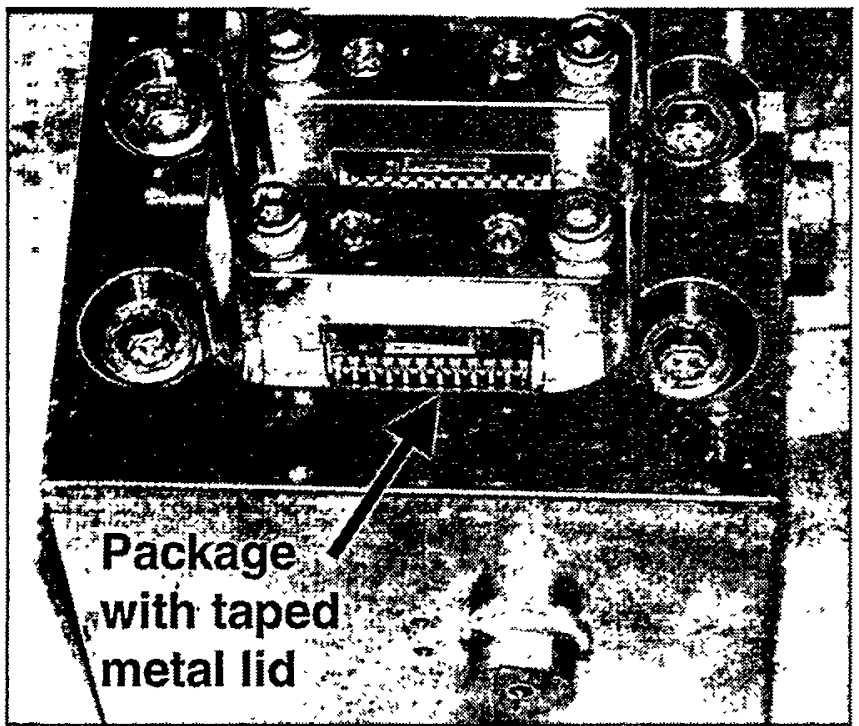

Figure 5 'The fixture in the vibration test clamped the packages in place to prevent movement.

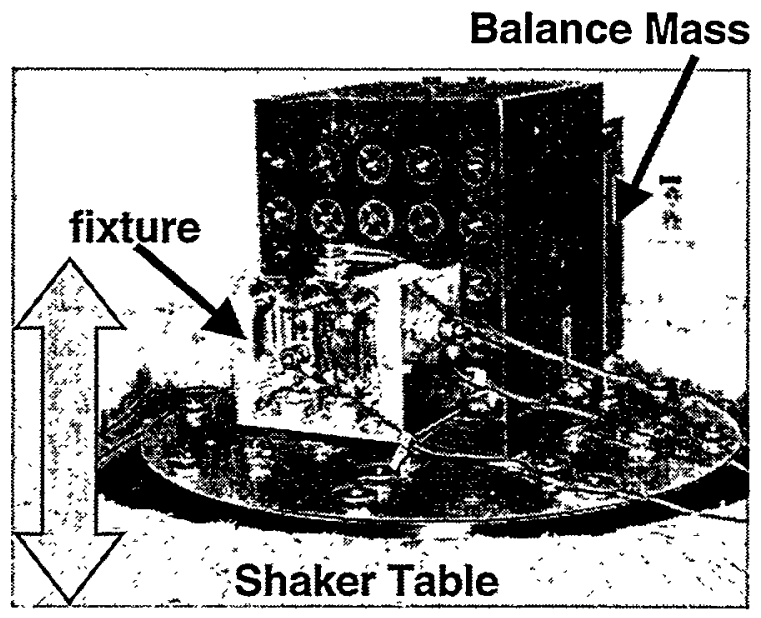

Figure 6. This photograph of the shaker table shows the fixture attached to the mounting cube for long side vibration. The arrow indicates the vibration direction.

\section{RESULTS AND DISCUSSION}

\section{Initial test}

The initial test was highly successful with 13 out of 14 microengines surviving and functioning at the $1 \mathrm{~Hz}$ inspection speed with no observable damage. We observed no stiction or misalignment problems in the microengines tested in the top/bottom orientation. The only overall effect noticed after vibration was a small change in the location of debris along the surface of the packaged die. Figure 7 shows the before and after images of debris movement. The vibration direction was long side as indicated in the figure. These long slivers of debris typically arise from the edge of the die where the stacked layers of the surface-micromachining process are exposed after sawing. Manipulation of the die with tweezers during the release may have caused the slivers to lie on the combs. Although we didn't observe it here, the slivers are a perfect candidate for shorting between the opposing fingers and the ground plane.

The possibility of producing wear debris from this experiment was also addressed. The regions of the microengine most susceptible to wear were investigated. These regions include the hub and pin joint, spring anchors, and shuttle guides. SEM characterization of these areas did not reveal the presence of wear debris resulting from vibration. As illustrated in figure 8 , the hub and pin joint regions do not show the presence of wear debris.

There was an apparent failure in one case due to a short of the power signal bond wire in the package. After the packaged part was tested in a 24-pin dip fixture, the microengine was then tested on a manual prober, thus bypassing the package. Using the manual probe station, the part functioned properly indicating the failure was not in the MEMS device but rather somewhere in the package or wire bonding. Because we are only interested in microengine functionality, the ability for the device to work on a manual prober was considered a successful pass of the vibration test. 


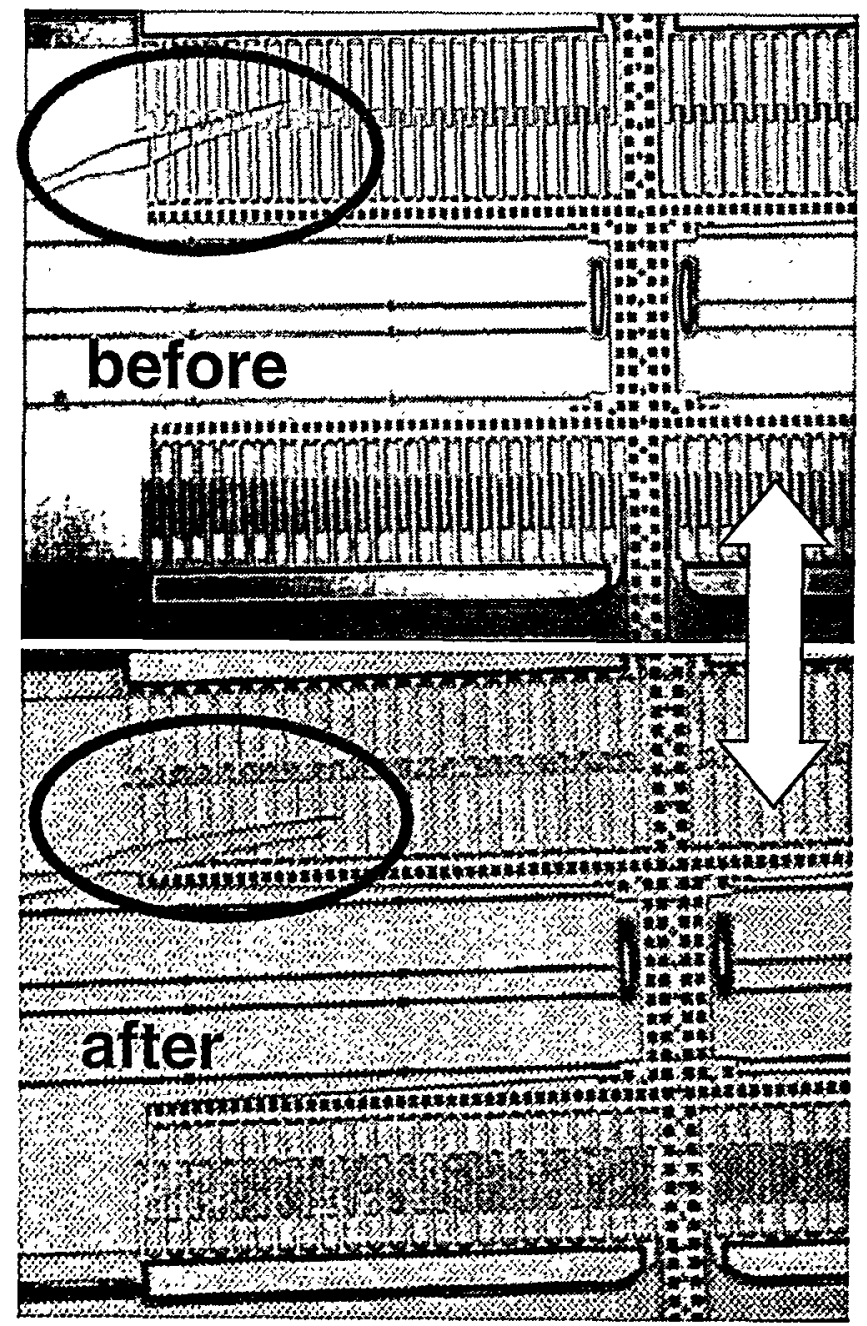

Figure 7. Example of debris movement as a result of the vibration. The double tipped arrow indicates the long side vibration direction.

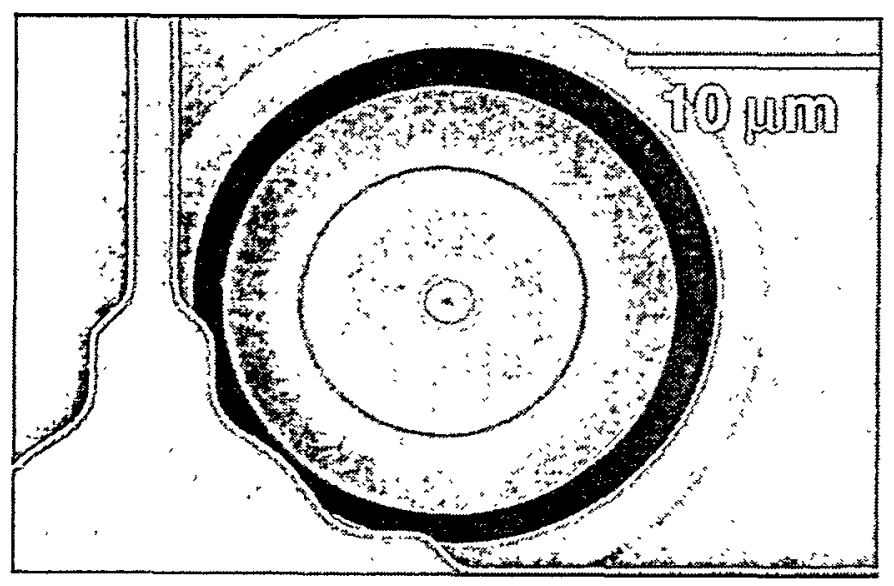

Figure 8. Hub and top portion of the pin joint after vibration. Note the lack of wear debris within the hub area and pin joint (lower left).

Broken pin joint failure: The only microengine failure in the initial test was due to a broken pin joint as seen in Figure 9 with th double-tipped arrow indicating the vibration direction. Our previous observations $[16,17]$ of broken pin joints were due to wear under

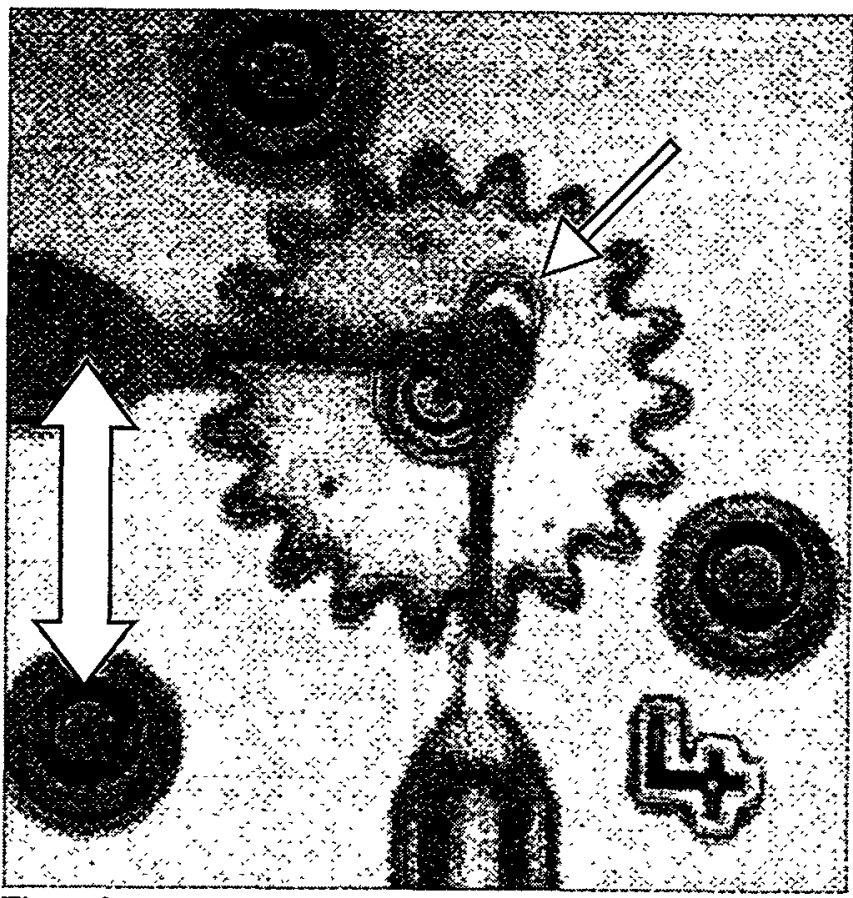

Figure 9. The linkage arms were disconnected from the gear thereby breaking the pin joint in the region indicated by the arrow. The double-tipped arrow indicates long-side vibration direction.

this case, the wear caused a reduction in the diameter of the pin joint from 3 microns to less than 1 micron.

Was there enough force in this test to shear a pin joint? The polysilicon pin joint has a 2 -micron diameter yielding a crosssectional area of $3.1 \mu \mathrm{m}^{2}$. The force needed to shear the pin can be estimated from $\tau=F / A$ where $\tau$ is the polysilicon shear strength, $F$ is the force, and $A$ is the cross-sectional area. Using maximum-shearstress theory [18], the shear strength for polysilicon is simply half of the fracture strength which has been measured [19] at $1.5 \mathrm{GPa}$. Therefore, a force of $2.4 \mathrm{mN}$ would be needed to shear the pin.

We can estimate the forces involved in the vibration assuming that the peak acceleration is $120 \mathrm{~g}$. The mass of the moving shuttle, combs, and springs is $1 \mu \mathrm{g}$. If we simply use $F=m a$, the peak force from the vibration was $1.2 \mu \mathrm{N}$, which is clearly over three orders of magnitude lower than necessary for shearing. A typical force used to rotate the microengine is 10 to $15 \mu \mathrm{N}$ and normal operation does not shear pins. Hence, the peak acceleration due to the vibration was not enough to shear a pin joint,

If the pin joint was damaged (crack initiation point) prior to testing, or a processing defect was present in the pin joint region, the vibration could cause crack propagation. Taking a closer look at the severed pin joint using a SEM reveals the fractured surface of the broken pin joint. Figure 10 shows both plan view and tilted characterization ( $40^{\circ}$ tilt along the z-axis) of the surface. In (b) the image reveals the pin joint fractured diagonal to the ground plane.

When the functionality of the broken-pin-joint microengine was tested, the linkage arms moved over the gear and reconnected to the bottom portion of the pin joint. Once this reconnection was established, the motion of the gear and linkage arms appeared normal at the inspection frequency of $1 \mathrm{~Hz}$. However, running this microengine at high speeds $(>500 \mathrm{~Hz}$ ) would disconnect the linkage arms at the broken pin joint again. 


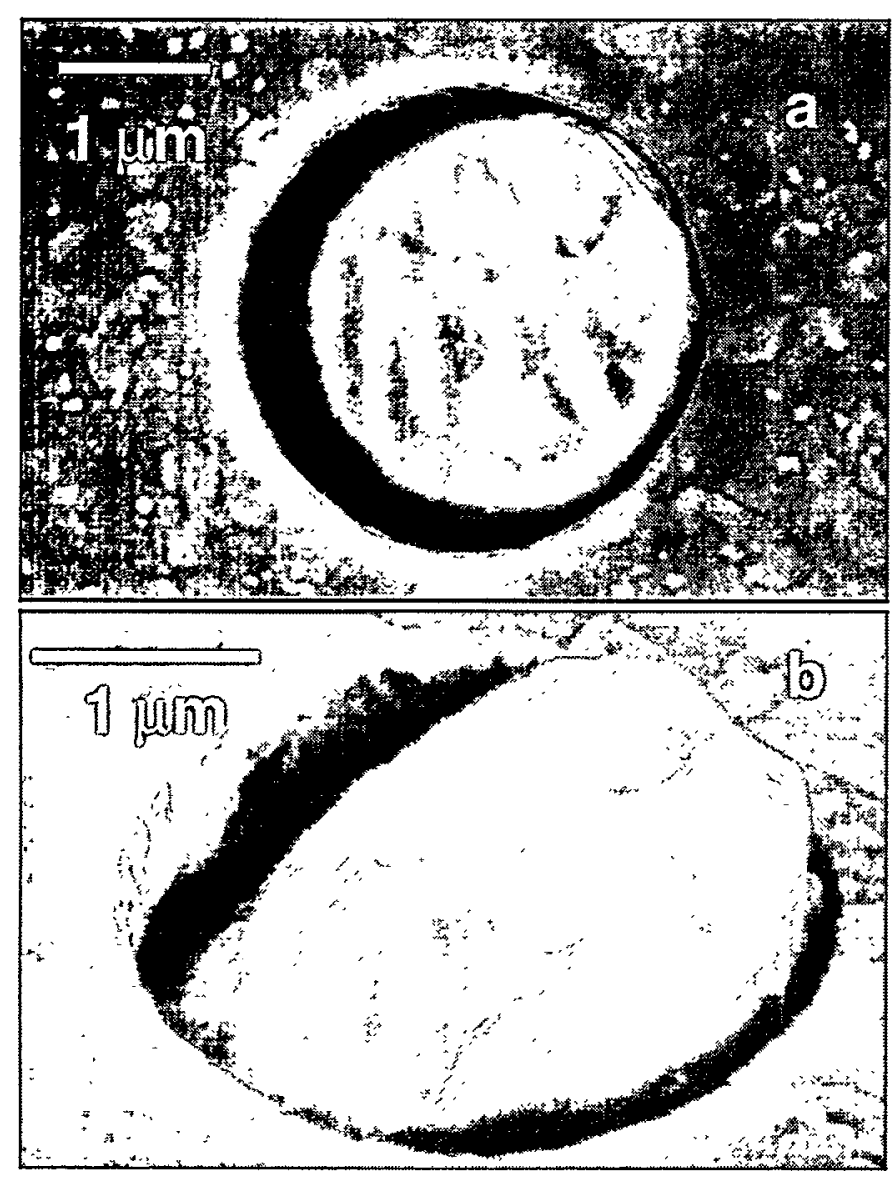

Figure 10. Plan view (a) and tilted (b) images of the broken pin joint illustrated in Figure 9. Note the fracture surface of the pin joint in (b) is diagonal to the ground plane.

\section{Repeat test}

In order to investigate the pin-joint failure, a repeat of the long side vibration test was conducted. The results of stressing 16 additional microengines (eight functional and eight nonfunctional) resulted in no broken pin joints.

Out of the eight functioning microengines on the repeat test, four failed to function properly at the inspection speed of $1 \mathrm{~Hz}$. One microengine attempted to rotate and immediately adhered to one of the guides. Removal of the guide by manually probing eliminated the adhesion point and allowed that microengine to operate momentarily, but it stuck again.

The other three failures exhibited a rocking behavior when we operated the microengine. The gear would not quite make a complete revolution, but instead rocked. Electrical probing of the drive signals revealed that some of the operational voltages were shorted to the ground plane. The shorted voltage (lack of drive signal to the actuator) explains the rocking signature.

After observing shorts in the vibrated microengines, we tested our controls that were kept in a benign nitrogen environment during the vibration test. Four out of nine microengine controls had failed by rocking. Once again, electrical probing revealed shorting of the operational voltages to the ground plane.

Adhesion failure: SEM analysis of the microengine that failed due to adhesion revealed the $Y$ shuttle was stuck to a rear guide near the actuation pads. The rear guides along the $x$-axis were removed from the device, and the device began to function. However, shortly after functioning, the device went back to its stuck position indicat- ing that removal of the $\mathrm{x}$-axis back guides momentarily freed up the shuttle but was not the source of the sticking. SEM characterization revealed the sticking site to be the rear guides along the $y$-axis actuator as illustrated in Figure 11. Note that the shuttle is attached to springs that restore it to the rest (initial) position. The double-tipped arrow in the figure indicates the vibration direction that, in this case, promoted rubbing between the shuttle and the guide. Here the shuttle is deviated to the right, leading to contact along the upper portion of the guide (circled region). Closer examination shows the upper level of the guide in contact with the top portion of the shuttle. No debris could be found near the failure region, indicating it is an adhesion failure and not a failure resulting from impact debris.

It is also interesting to note that the shuttle appears to be elevated from its initial position even though the restoring springs are attempting to pull it down. Further characterization into this area reveals the top portion of the shuttle is contacting the bottom overhanging part of the guide as revealed in Figure 12. Although the failure site as been characterized, the reason for the shuttle lifting and contacting the bottom portion of the overhanging guide is not known at this time.

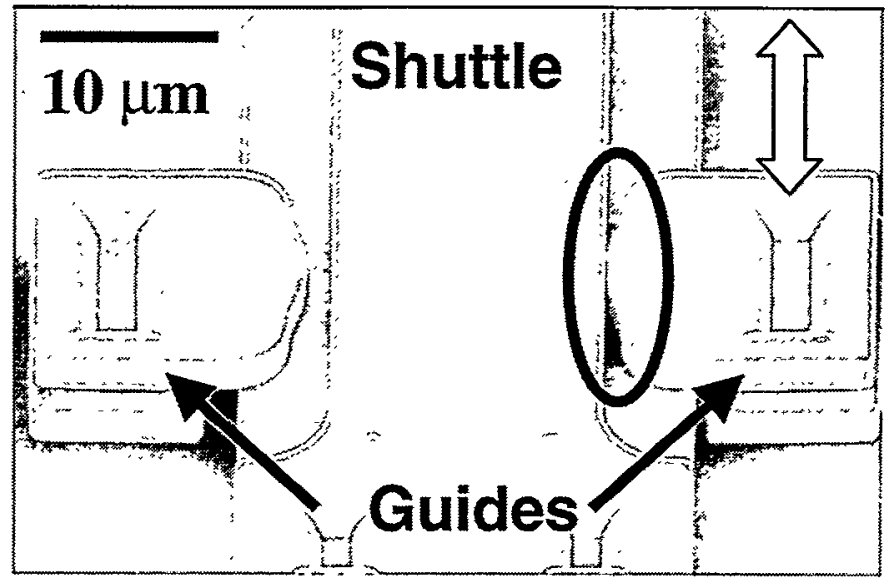

Figure 11. Adhesion failure sight in a microengine.

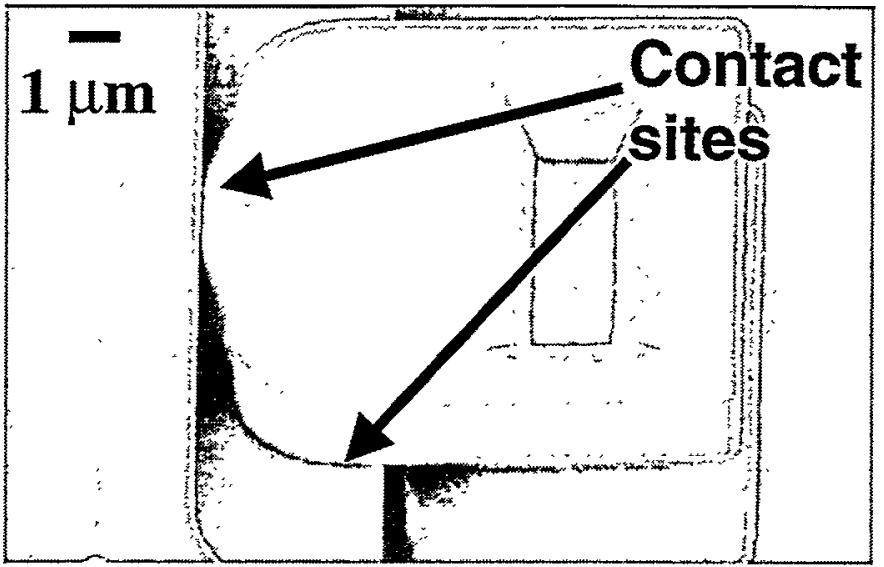

Figure 12. Close up image of the adhered region of the microengine.

Electrical short failure: Through the course of the experiment, a novel failure mode was discovered. This failure mode can be diagnosed as a short of a drive signal to the ground plane. The physical signature that has been associated with this failure mechanism has been defined as a rocker. This occurs when there is a failure of one of the drive signals to induce actuation on a set of comb fingers. To thoroughly investigate this new failure mode, the focused ion beam (FIB) was used to extract the mobile shuttle and comb fingers to 
permit unobstructed viewing of the bottom level of polysilicon comb fingers. Analysis could be conducted with the shuttle intact, but any defects that may occur on the bottom level of the comb fingers from the side would be obstructed from the comb fingers as illustrated in figure 13.

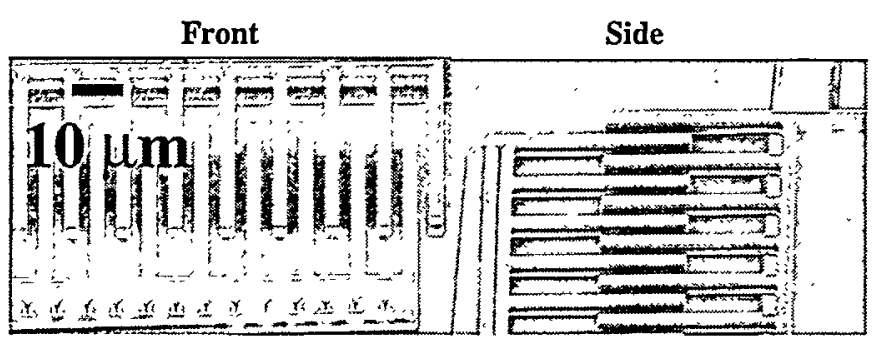

Figure 13. Front and side views of a $40^{\circ}$ tilted micromachine comb drive actuator. Note the tips of the comb fingers can be viewed, but the mobile shuttle obstructs characterization from the side of the stationary comb fingers.

The FIB cuts involved severing nine polysilicon lines as indicated by the dark lines of Figure 14. Here, nine FIB cuts were made along thin regions of polysilicon located at the front and back anchors (four FIB cuts per anchor). The ninth FIB cut is performed at the flexure located just before the linkage arm connecting the shuttle to the gear. The released shuttle was then removed from the microengine utilizing a probe tip with a sticky adhesive at the tip of the probe. This method removed the shuttle without inducing damage along the stationary comb fingers.

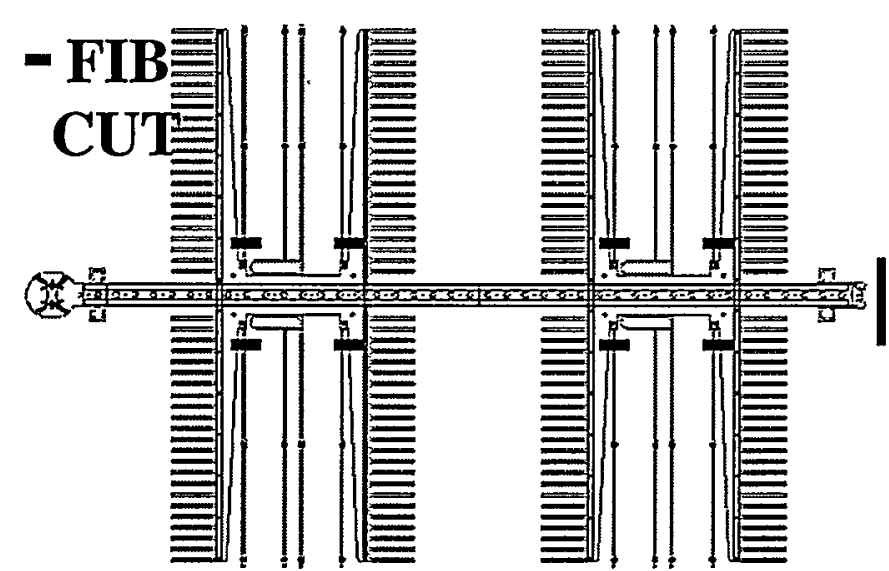

Figure 14. AutoCad rendered image of a Sandia fabricated comb drive actuator. Each thick line indicates a region where a FIB cut has been performed ( 4 for each spring anchor, and one for the flex arm).

Investigating the electrical short failure using a SEM revealed a polysilicon comb finger adhered to the polysilicon ground plane as shown in Figure 15. Although this failure may appear to be "stiction" related, it is not. Stiction-related failures occur predominantly during the release process. These microengines were released and characterized both optically and electrically. Both inspections did not reveal the presence of adhered comb fingers. This indicates the comb finger somehow adhered to the ground plane to induce failure after the initial inspection.

Upon further SEM inspection, residual material is present at the tip of the comb finger as illustrated in Figure 16. Characterization and experiments are currently underway to determine if the material is a result of particular contamination, residue along the comb finger, or arcing due to electrostatic discharg (ESD). In either case, the direct result is a short of a bottom comb finger to the ground plane.

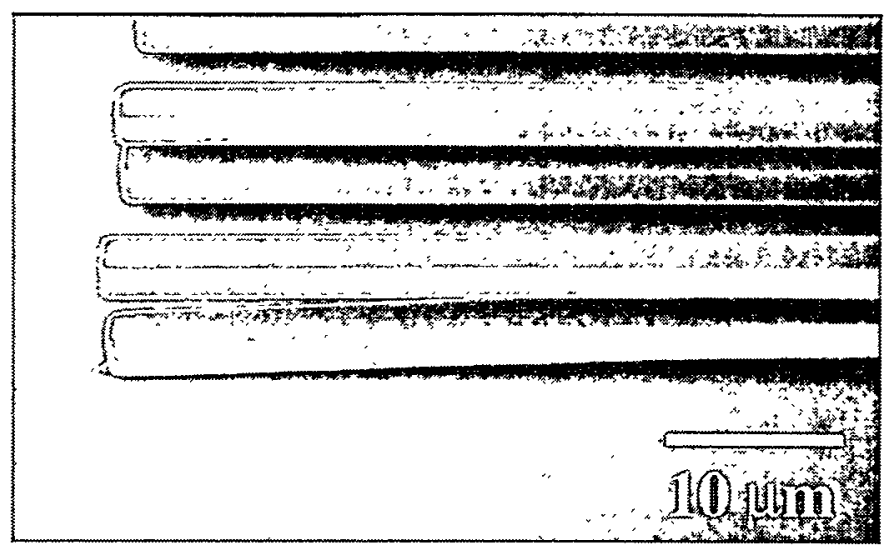

Figure 15. Polysilicon comb finger adhered to the ground plane.

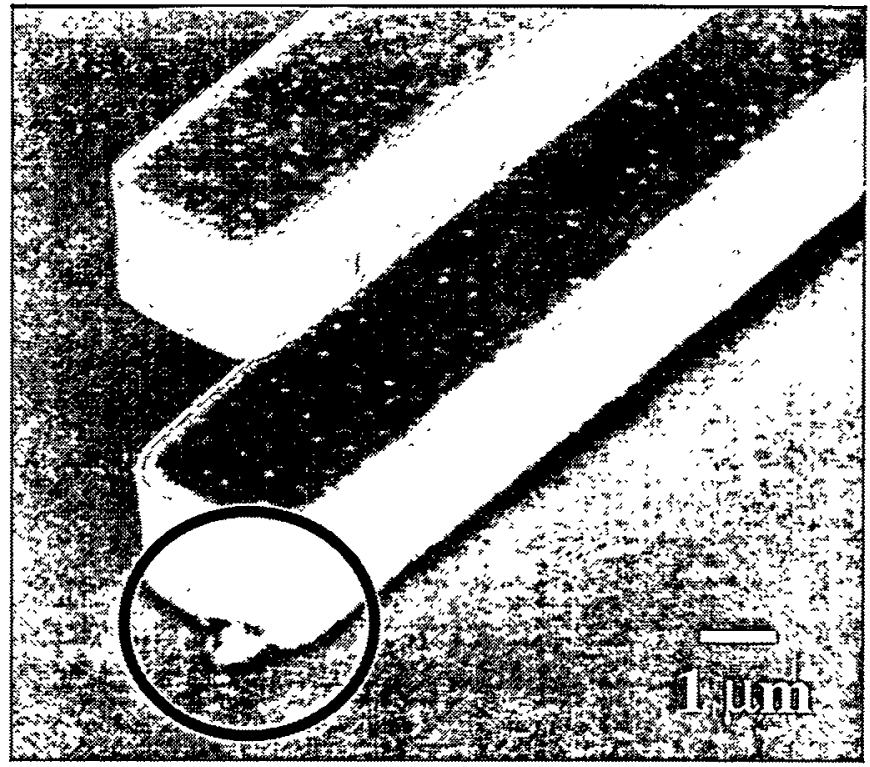

Figure 16. Close up SEM image of the adhered comb finger of Figure 15. Residual material is present at the tip of the comb finger (depicted in the circled region).

Overall failure discussion: At this point, we are unclear if the vibration caused the pin joint failure. However, it cannot be ruled out. We categorized this failure mechanism as anomalous since it could not be duplicated upon similar experimental conditions. This result indicates that there may have been an initial flaw in the pin joint, or the pin joint suffered some form of damage prior to testing which the vibration acerbated.

The adhesion failure was vibration related. The direction of the vibration promoted the rubbing of the moving shuttle and the guide. We suspect that the rubbing caused the adhesion.

Because the three electrical short failures in the repeat test were duplicated in the controls, we can assume that they were not due to vibration.

In all, we observed two failures out of a total of 19 microengines tested (eliminating the three shorts) which implies a $90 \%$ pass rate for a vibration stress set to four times our typical system requirement. 


\section{CONCLUSIONS}

In our vibration stress tests at four times the level of our typical system requirement, we observed a 90\% success with only 2 failures out of 19 tested. The vibration spectrum had a peak acceleration of $120 \mathrm{~g}$ and was equivalent to roughly $5 \times 10^{5}$ oscillations but it produced no wear debris along the rubbing or impacting surfaces in the microengines. Movement of slivers of debris was observed, but it caused no failures. However, the potential for failure exists where a piece of debris can bridge the gap between the comb drive and ground plane resulting in a direct short. Steps should be taken to eliminate the debris.

We observed a broken pin joint, but it is unclear if this was due to the vibration. The other failure was due to adhesion after rubbing from the vibration. Perhaps the most surprising failures were those not related to vibration, but due to shorted comb fingers to the ground plane. Investigations are underway to determine the cause of the short. We suspect these shorted failures may be the result of handling of the MEMS devices, or residual material present along the tips of the bottom comb fingers prior to testing.

\section{ACKNOWLEDGMENTS}

The authors thank the personnel of the Microelectronics Development Laboratory at SNL for fabricating, releasing, and packaging the devices used for this test. We acknowledge the help of Bill Eaton for macro writing to make the documentation easier, Nathan Masters and Tom Krygowski for reviewing the report, and Alex Pimental for the FIB work.

Sandia is a multiprogram laboratory operated by Sandia Corporation, a Lockheed Martin Company, for the United States Department of Energy under Contract DE-AC04-94-AL85000

\section{REFERENCES}

[1] T. G. Brown and B. Davis, "Dynamic High-G Loading of MEMS Sensors: Ground and Flight Testing," SPIE Proceedings, Vol 3512, 1998, pp. 228-235.

[2] D. M. Tanner, et al., "The Effect of Humidity on the Reliability of a Surface Micromachined Microengine," Proc. of IRPS, 1999, pp. 189-197.

[3] S. T. Patton, W. D. Cowan, and J. S. Zabinski, "Performance and Reliability of a New MEMS Electrostatic Lateral Output Motor," Proc. of IRPS, 1999, pp. 179-188.

[4] http://www.mdl.sandia.gov/Micromachine/

[5] S. S. Lee, E. Motamedi, and M. C. Wu, "G-Performance Characterization of Surface-Micromachined FDDI.Optical Bypas Switches, Proc. of SPIE, Vol. 3226, 1997, pp. 94-101.

[6] L. S. Huang, S. S. lee, E. Motamedi, M. C. Wu, and C. J. Kim. "MEMS Packaging for Micro Mirror Switches," Proc. of $48^{\text {th }}$ Electronic Components and Technology Conference, Seattle, WA, 1998, pp. 593-597.

[7] K. J. Gabriel, F. Behi, and R. Mahadevan, "In situ Friction and Wear Measurements in Integrated Polysilicon Mechanisms," Sensors and Actuators, A21-A23, 1990, pp. 184-188.

[8] M. Mehregany, K. J. Gabriel, and W. S. N. Trimmer, "Integrated fabrication of polysilicon mechanisms," IEEE Trans. Electron Devices, ED-35, 1999, pp. 719-723.

[9] D. M. Tanner, W. M. Miller, W. P. Eaton, L. W. Irwin, K. A. Peterson, M. T. Dugger, D. C. Senft, N. F. Smith, P. Tangyun- yong, and S. L. Miller, "The Effect of Frequency on the Lifetime of a Surface Micromachined Microengine Driving a Load," IEEE International Reliability Physics Symposium, Reno, NV, 1998, pp. 26-35.

[10] E. J. Garcia and J. J. Sniegowski, "Surface micromachined microengine", Sensors and Actuators A, Vol. 48, 1995, pp. 203-214.

[11] R. Maboudian and R. T. Howe, "Critical Review: Adhesion in surface micromechanic structures," Journal Vac. Sci. Technol., B 15(1), Jan/Feb 1997, pp. 1-20.

[12] R. Maboudian and R. T. Howe, "Stiction reduction processes for surface micromachines," Tribology Letters, 3, 1997, pp. 215-221.

[13] M. R. Houston, R. T. Howe, and R. Maboudian, in $8^{\text {th }}$ Int. Conf. On Solid-State Sensors and Actuators (Transducers '95) and Eurosensors IX, Vol.1 Stockholm, June 1995, pp. 210-213.

[14] R. L. Alley, R. T. Howe, and K. Komvopoulos, Proceedings of the IEEE Solid-State Sensor and Actuator Workshop, Hilton Head, SC, 1992, pp. 202-207.

[15] C. M. Harris and C. E. Crede, Shock and Vibration Handbook, McGraw-Hill, 1976, Chap. 11.

[16] D. Tanner, W. Miller, K. Peterson, M.Dugger, W. Eaton L. Irwin, D. Senft, N. Smith, P. Tangyunyong, and S. Miller, "Frequency dependence of the lifetime of a surface micromachined microengine driving a load," Microelectronics Reliability, 39, 1999, pp. 401-414.

[17] J. A. Walraven, T. J. Headley, A. N. Campbell, and D. M. Tanner, "Failure Analysis of Worn Surface Micromachined Microengines," Proc SPIE, Vol. 3880, 1999, pp. 30-39.

[18] J. E. Shigley and C. R. Mischke, Mechanical Engineering Design, McGraw-Hill, 1989, Chap 6.

[19] W. N. Sharpe, Jr., K. T. Turner, and R. L. Edwards, "Tensile Testing of Polysilicon," Experimental Mechanics, vol. 39, no.. 3, 1999, pp. 162-170. 